\title{
New Public Management, Cost Savings and Regressive Effects: A Case from a Less Developed Country
}

\section{Introduction}

Given the open nature of the social system, human actions can always result in unanticipated outcomes (Merton, 1936). Perhaps because of the drama associated with the subject, this has always been an area of interest to fiction writers and academic researchers alike (Smith, 1776; Ross, 1996). Eminent scholars from the fields of sociology, economics, and organisation studies have thus studied the conditions or the paths that lead to unintended outcomes of social actions. Public sector reforms, including new public management (NPM), are also known to be prone to unintentional and surprise outcomes (Merton, 1936; Spencer, 1946; Hood, 1998; Hesse et al., 2003), and the paradoxes and unintended outcomes of NPM have become an important area of investigation for researchers (Hood and Peters, 2004). Management accounting and control forms a very important part of NPM (van Helden, 2005), and accounting researchers have already documented the issue of unintended consequences of management accounting and control reforms (Laughlin et al. 1994; Broadbent et al., 2001). However, given the significance and the frequency with which this phenomenon is encountered, the issue of unintended consequences of management accounting and control reforms requires more focused scholarly attention. This paper is an attempt to analyse a particular type of unintended consequence in a public sector organisation, i.e., the 'regressive effects' ${ }^{\mathrm{i}}$ of intended management accounting and control reforms. As will be explained later in the theoretical framework section, 'regressive effects' are different from the unintended consequences of reforms, e.g., null effects or side effects. Despite the academic and policy significance of regressive effects to public sector reforms, the area remains under researched and under theorized.

The empirical site of this research is a public sector organization in Pakistan, namely, Civil Aviation Authority (hereafter CAA), which underwent a series of management accounting and control reforms. 
These reforms are reported to have increased the number of safety breaches and to have given rise to lifethreatening situations (Khan, 2008). The case study thus presents us with an excellent opportunity to study and theorise the dynamics of reform, in our case, the regressive effects of reform. Locating Sieber's (1981) work on regressive effects of reforms in a critical realist tradition (Bhaskar, 1979; Sayer, 1992; Archer, 1995), the paper develops a processual model of regressive effects. We seek to make an important contribution to the field of cost management reforms in less developed countries by understanding the 'structural conditions' and 'agential actions' that lead to regressive results.

The paper begins with a brief review of NPM studies in relation to management control changes and outcomes in both developed and less developed countries; this is followed by a section on the theoretical framework on the regressive effects of reforms. The paper then briefly explains critical realist interpretations of regressive effects followed by a description of the research methods. The empirical findings are presented and discussed, leading to theoretical discussions and conclusions in the final section.

\section{NPM, Management Controls, and Outcomes}

NPM involves the autonomisations of large public sector organisations into smaller units and the introduction of market or (quasi market) competitiveness within these units (Diefenbach, 2007), akin to the environment of private organizations. Once these organisations are exposed to the market competitiveness, a private sector management style also becomes relevant. This includes a cost control and audit culture, greater managerial discretion, specific performance measures linked with outputs rather than processes, the evaluation of performance against pre-established standards and economic efficiency (Hood, 1991). The move is intended to make public sector organisations more 'business like', i.e. a greater focus towards cost management, performance measurement and audit (Diefenbach, 2007). Since NPM involves prioritising economic efficiency, cost control, and performance measurement and audit, 
the increased importance of (management) accounting was an expected feature of this movement (Power and Laughlin, 1992).

In a series of very insightful papers, Jane Broadbent and Richard Laughlin, with various colleagues (see Laughlin and Broadbent, 1993; Laughlin et al., 1994; Broadbent and Laughlin, 1998; Broadbent et al., 2001), analysed NPM-related changes in the management accounting and control of different public sector areas, in particular, the healthcare and the education sectors in the UK. Drawing on the Habermesian notions of 'life-world' and 'steering mechanisms'; Broadbent and Laughlin's works provided detailed accounts of 'unsuccessful' reforms including theorisation of varying degrees of resistance to these management accounting changes. They argued that resistance strategies of actors depend on the level of perceived threats (Laughlin and Broadbent, 1993; Broadbent and Laughlin, 1998). Weak threats encourage organisational members to adopt 'absorbing' strategies leading to work 'as before' while accommodating the demands of the state (Laughlin et al., 1994). If, however, the threat level was great, then a more open resistance strategy was adopted (Broadbent et al., 2001).

Public-sector organisations operating in less developed countries have unique historical, cultural, and political circumstances (Hopper et al., 2009). Most of the less developed countries have gone through a similar historical transformation: independence from a colonial power during the middle of the twentieth century, state-led industrialisation cum central planning during the 1950s, and privatisation and NPMrelated reforms during the 1980s and 1990s (Alawattage et al., 2007). Most of these shifts in policy are often a function of international politics and of the economic dependence of these countries on economically stronger nations (ibid). This political and economic context has had a direct bearing on the management accounting and control practices of public sector organisations in less developed countries (Hopper et al., 2009). First, in most of these public sector organisations, 'bureaucratic' management accounting and controls were in place to enable the state to make rational decisions about resource allocations. However, in practice, politicians often interfered with these formal rules (Alawattage and 
Wickramasinghe, 2009). Most of these public sector organisations suffered heavy losses partly due to this political interference, thus adding to the economic burden of the state.

Subsequent changes to management controls in the public sector were generally linked with poor financial performance followed by 'reform' programmes advised by international lending agencies (Uddin and Hopper, 2003; Hopper et al., 2009). These reforms took the form of partial or full privatisation of state-owned entities (Uddin and Hopper, 2001; Wickramasinghe and Hopper, 2005, Uddin and Tsamenyi, 2005). However, in most of these cases, the 'reforms' did not materialise because of a host of factors normally linked with local politics and bad governance. In some cases, especially privatised organisations, management controls took a more exploitative shape whereby both the labour force and the state were the ultimate losers, while the new owners benefited (Uddin and Hopper, 2001). In those organisations that were not privatised, not much changed in terms of management accounting and control practices (Uddin and Tsamenyi, 2005). Thus, current research on management accounting and control in less developed (as well as developed) countries has revealed a number of cases where either the efforts at reform did not produce any results, i.e., the conditions remained exactly the same, or the reforms produced unintended and undesired results (Gallhofer and Haslam 1991; Uddin and Hopper, 2003; Wickramasinghe and Hopper, 2005; Lapsley, 2009).

At a generic level, countries appear to adopt a globalised standardised NPM model; however, a closer examination reveals that this is far from being the case (Guthrie et al., 1999; Pollitt, 2001). Drawing on eleven national case studies, Guthrie et al., (1999) argued that the type and degree of New Public Financial Management systems varies significantly from country to country. Pollitt and Bouckaert (2011) also noted considerable differences in nature, processes and outcomes of the NPM reforms and concluded that the reforms have not been as successful as claimed by their proponents and more importantly, the reasons for the 'failure' or 'success' of these reforms may vary depending upon material and cultural circumstances of individual countries. The very nature of contested reforms reflects a clash in 'life-world' of different agents running the public sector organisations as much as a clash of material interests of 
agents involved (Broadbent and Laughlin, 1998; Townley, 2002). A deeper understanding of NPM related changes, including the regressive consequences, thus require a better appreciation of material and cultural circumstances surrounding specific reforms within a specific sector or organisation (Guthrie et al., 1999; Pollitt and Bouckaert, 2011)

This research is an effort to understand the specific circumstances that led to the 'failure' of reform efforts in a public sector organisation in Pakistan. It specifically addresses one particular and perhaps the worst form of 'failure', i.e., regressive effects of reforms. Our research aims are thus more in line with the work of Michael Power (Power, 1994, 1997), who explored the regressive effects of the UK becoming an 'audit society'. According to Power (1997), reform efforts aimed at improving quality of public service through 'auditing' all public services have eventually led to regressive effects whereby 'auditability' of service has become a primary consideration at the expense of quality of service thus causing a decline in quality of services delivered. In order to collect and analyse the empirical data, we have employed the theoretical guidance provided by critical realist scholars (Sayer, 1992; Archer, 1995) using Sieber's (1981) work on the 'regressive effects of social reforms' as a substantive theory to shed light on the cost management reforms carried out at CAA. This will be further explained and justified below.

\section{Reforms and Regressive effects}

The issue of unintended consequences of human actions has been an important area of social inquiry. In classical sociology, it is famously associated with Marxist ideas of historical dialectics whereby the actions of capitalists will eventually inspire the working class revolution, thus ultimately undermining the capitalist mode of production. Similarly, Herbert Spencer (Spencer, 1946) identified the regressive effects of state interventions in the natural evolution of markets. Spencer thus became a strong opponent of state interventions in the 'laws of demand and supply', which according to him, exacerbate the situation rather than rectify it. 
Amongst contemporary sociologists, Robert Merton theorised the unintended consequences of purposive human action, identifying three actor centric explanations that can lead to unintended outcomes (Merton, 1936). They include lack of knowledge, the error of judgement, and the immediacy of the interests of the actors. Inspired by Merton's work and locating it in the realm of the public sector, Sieber (1981) identified seven mechanisms that in isolation or collectively convert managerial reforms into regressive effects: functional disruption, exploitation, goal displacement, provocation, labelling/classification, overcommitment, and placation. Actors remain at the centre of these mechanisms. Sieber (1981) explained in detail as to how each one of these mechanisms, on its own, can lead to regressive effects in public sector reforms. In some cases however, Sieber (1981) contends that more than one mechanism can be at play, eventually leading to regressive reforms. Sieber (1981) suggests that it is up to the researchers to identify one or a combination of more than one mechanism that causes regressive reforms in a specific empirical situation. We wish to examine reforms at CAA to identify one or a combination of mechanisms that caused regressive consequences. The explanations of each of these relevant mechanisms will be iterated with empirical findings presented later.

Sieber's explanatory mechanisms seem to be tied to agential strategies (the actions and/or intentions of 'reform' agents and the re-action of the target population), ignoring the role played by the structural conditions (both material and cultural context). Actions of agents are likely to play an important role in creating social consequences, regressive or otherwise. However, actions and reactions of agents do not take place in a vacuum (Sayer, 1992, p.63). Critical realists argue that structural conditions cause the agents to act in a certain manner (Archer, 1995). However, while admitting the significance of the 'context', Sieber (1981; p.6) does not theorize as to how the structural conditions are implicated in regressive consequences. The analysis and theorization of structural context becomes especially important for explaining varying causes and trajectory of reforms in different cases (Pollitt and Boukaert, 2011). A critical realist approach to Sieber's work is thus appropriate as it draws the focus of the researcher towards identifying unique material or cultural conditions surrounding the agents involved in the reform 
project. At the same time, it pays attention to agents' actions and strategies (Bhaskar, 1979; Sayer, 1992; Archer, 1995). This will be further justified below.

\section{Regressive effects: A Critical Realist Inquiry}

Critical realism is a social science meta-theory pioneered by Roy Bhaskar (Bhaskar, 1979; 1997). The basic premise of critical realism is that it is not appropriate to focus exclusively on the actions of agents in order to understand empirical events, e.g., regressive effects. Empirical events are caused by an underlying system of relations between positions and objects that have the causal powers to produce empirical events. Critical realists divide relations between positions and objects into two types, internal and externali (Sayer, 1991; p74). It is the internal relations between objects and positions which are of most interest to critical realist scholars. A typical example is the system of internal relations between the positions of capitalists, managers, and labour in a capitalist mode of production. The relations between these positions are internal because none of these positions can exist without the other. The internal relations between these positions cause certain behavioural tendencies on the part of the agents occupying these positions, e.g., competition, intensification of labour, exploitation, and resistance. Situating agents in the underlying system of internal relations would provide much better explanations of their actions. The term used by critical realist scholars to describe this underlying system of internal relations between positions is 'structure'.

The underlying structures provide position-holders with certain 'interests' and constraints to act. Agents invariably occupy multiple and often contradictory positions at the same time within different system of relations (structures) e.g. family, religion, profession, and ethnicity. These structures provide positionholders 'ideal interests' to pursue. 'Ideal interests' drawn from cultural belief system expose agents with alternative reasons for acting in a manner, which may go against their material interests (Archer, 1995; p211). For example, certain economic conditions may cause the capitalists to extract more from the labour, and the failure to do so may result in severe damage to economic interests. However, the 
possibility of a 'lenient approach' towards the labour in the face of tough economic conditions cannot be ruled out because those agents are not just 'labour but also 'fellow Christians' or 'fellow Sinhali' (Wickramasinghe and Hopper, 2005). Incorporation of cultural conditions and ideal interests, thus brings critical realism very close to the notion of institutional logics (Mutch, 2007).

Critical realism avoids structural determinism by incorporating the notion of reflexivity (Archer, 1995; 2003). Multiple subject positions open up space for human agency in terms of subjective 'weighing' of these multiple structural pressures by the agents (Archer, 1995). Subjective weighing of these multiple and divergent structural pressures mean that agents' actions are far from being a rational choice with an eye on material consequences. At the same time, these actions are not an irrational leap drawn from values developed in the past (Archer, 1995; p 210). Instead this weighing takes place in the light of agents' past experiences and commitments, future aspirations and fears, and a 'feel' for the practical exigencies of the situation at hand (Emirbayer and Mische, 1998; Mutch, 2006). This anchoring in the past, with imaginative projections of the future and keeping in view the immediacy of the present mean that critical realist conception of agency is neither completely normative, nor radically instrumental and voluntary (Archer, 2003; Mutch, 2007). It is this triad concept of agency in critical realism; incorporating the past routines, the present judgement, and the future projections that distinguishes it from theoretical frameworks like institutional theory which emphasize the past routines or norms ${ }^{\mathrm{iii}}$; or rational choice theories, which emphasize future purposivity (Emirbayer and Mische, 1998).

In all social situations, structures and agency are intertwined. However, to understand empirical phenomena through critical realist inquiry, researchers need to analytically separate the two ${ }^{\text {iv }}$ (Archer, 1995). Adopting a critical realist research approach thus requires researchers to first identify all structures (material or cultural) in which agents are enmeshed including the conditioning effects of this structural context (Archer, 1995). Once these structural conditions are identified, the researchers should focus on the agency i.e. reflective or routine actions of agents. These agentic efforts may result in changes in some 
structural conditions, which will have conditioning effects on the next cycle of agents' actions (Archer, 1995). This approach of analytical separation of structure and agency and the examination of their interplay to produce empirical events is the essence of critical realist inquiry (Sayer, 1991).

Critical realism has increasingly been appropriated by organizational and management studies (Ackroyd and Fleetwood, 2000; Willmott, 2000; Mutch, 2002; Fleetwood and Ackroyd, 2004; Leca and Naccache, 2006; Llewellyn, 2007) as well as accounting research (Modell, 2009 \& 2013; Ashraf and Uddin, 2013; Stergiou et al., 2013; Mutiganda, 2013). Reviewing the existing critical realist research on management accounting change, Modell (2014) noted that researchers tend to use critical realism in a generic manner i.e. without the use of any substantive theory. Protagonists of critical realism (Archer; 1995; Sayer, 1992; p91) have also recommended the use of substantive theory and critical realism as a broader theoretical approach to explain the empirical situation and to enrich the substantive theory. Recognizing the merits of this approach, we have used critical realism as a broad theoretical framework with Sieber's (1981) regressive reforms as a substantive theory. Our aim in this research is to understand the effect of structural context as well as the human agency that caused the regressive effects, thus making theoretical contributions in the field of regressive reforms in public sector and management accounting change. A diagrammatic model that represents the processual model of explaining the regressive effects of reforms can be seen in Figure One.

\section{[Insert Figure One]}

According to this diagram, first, we need to identify the structural conditions (SC1) that were influencing the actions of the agents on the scene by providing them with reasons for actions, either in the form of material or ideal/cultural interests. Second, agential strategies need to be identified. Two agentic actions A1 and A2 are identified reflecting on empirics and Sieber's mechanisms. A1 represents the rushing for reforms whereas A2 represents provoking the target population by trying to make the organisation 'lean 
and mean'; and its reaction in the form of resistance by target population. The resistance resulted in reform agents deciding to placate the target population, thus producing the first regressive outcome (RO1/SC2). This regressive outcome produced its own conditioning effects on further agentic actions. In the next sequence of agentic actions, denoted by A3, reform agents and target population became hostile, classifying each other as 'ignorant' and 'exploiting' the reform program, where the actual goal of cost management has been displaced by vested interests. This hostility resulted in a functional imbalance thus causing another set of regressive outcomes (RO2). The details of the model will be discussed with empirics in later sections followed by the research method section.

\section{Research Methods, Data Collection, and Analysis}

Conducting a social scientific inquiry in public sector organisations in less developed countries is marred with difficulties (Devereux and Hoddinott, 2002). A substantial amount of information lies behind 'closed doors' and in 'confidential files', not easily accessible by researchers. The professional connections of the first author with key agents in the case organisations provided us with the necessary access. In line with the traditions of critical realism, our data collection efforts focused on identifying structural conditions as well as agents' interpretations and actions. The data for this case study was collected during the year 2008 over a span of six months, including multiple visits to headquarters, two international airports and some visits to residences of respondents.

Important data sources for the identification of structural conditions included, first, a review of the historical literature of CAA, as well as the broader politico-economic historical literature, e.g., commentaries of analysts on Pakistan's political and economic situation, and about the public sector in general. The review was conducted with specific reference to identifying the structural conditions surrounding public sector organisations. As the next step, to develop a better understanding of the structural conditions faced by the managers of CAA, we also collected news reports relating to CAA and 
related organisations, which had appeared in the national and international media in the five years preceding the research. These news reports proved very useful for developing a general understanding of the structural conditions faced by managers of public sector organisations in general and CAA managers in particular. Another important source of information on the structural environment in which the managers of CAA were enmeshed included a review of official documents ${ }^{v}$.

Interviews were another important source of data for understanding the structural conditions as well as agents' actions. When our data collection period started, change efforts were already underway. We began interviews at CAA headquarters with senior management representing directors of various functions, followed by meetings with their immediate juniors. In total, $44^{\text {vi }}$ interviews were conducted with $37^{\text {vii }}$ respondents in three rounds. No formal group interviews or focus group discussions were conducted for this research. In the first round, 17 interviews were conducted. During this round of interviews, we interviewed some important reform agents, for example change team (5 interviews) and senior managers of different functional units (11 interviews) as well as an interview with a senior official from the Ministry of Defence. The first round of meetings gave us a general sense of what was happening in CAA in terms of cost management reforms. The second round of interviews at the headquarters was based on the knowledge acquired from the first round. The selection criterion for interviews for the second round was based on the principle of theoretical sampling (Mason, 2002). According to this principle, we chose respondents who were important for theoretical insights that we were trying to generate. In line with our theoretical aims, we were interested in understanding different management control changes that were taking place at the case organisation. In the second round, we conducted 19 interviews with 16 respondents including 4 interviews with members of the change team, 4 interviews with other reform agents (e.g. managers recently appointed within CAA for their commercial and managerial skills) and 11 interviews with senior managers of different functions. In the third round, 8 interviews were conducted with 7 respondents including the former Director Generals and senior officials of CAA (4 interviews) and reform agents (4 interviews). Interviews with key agents that had been 
associated with CAA in the past provided us with an understanding of historical structural conditions surrounding managers working within CAA. In addition to the formal interviews, we also had the


understand the thinking, aspirations and constraints felt by the change team. In terms of the location of the interviews, most of them took place at the work place while some, especially with retired officers, took place at their homes. The time period of interviews also varied. Some interviews lasted for more than two sessions. Most of the interviews lasted for about an hour or more.

We used notepads to record the interviews as they were taking place. We made every effort (to the best of our writing abilities) to ensure that we keep a verbatim record of all interviews. At the end of each interview, we shared with respondents our understanding of what they had said during the interview to provide them with an opportunity to endorse or amend anything that they had said. These interviews were further corroborated and complemented especially by directives and memos from the Director General's office. These directives provided a great insight into the perceptions, intentions, and actions of the Director General and other reform agents.

After the collection of data, the next stage was the analysis of these interviews. This analysis took two forms: one that led to uncovering the structural conditions and another that involved the agents' reception of these structural conditions, their strategies and actions. In accordance with the research traditions of critical realism, agents may not be aware of the structural conditions (material and cultural) affecting their actions; however, researchers can trace these structural conditions from their accounts (Sayer, 1992). For example, our interviews with the change team members helped us discover the structural conditions surrounding their appointments and the pressures that these conditions exposed them to. We triangulated these results with our findings from other data sources about the structural conditions. Similarly there were certain 'cultural conditions' that the target population, in their interviews, considered as important. For example, current generation directors considered themselves to be 'protectors' of employees working 
in their directorates. Our third round interviews with the first generation officials confirmed that these were longstanding cultural conditions which were continuing since the inception of the organisation.

The second line of analysis involved the identification of agents' reception of these structural conditions and their strategies. In this line of analysis, we developed codes that captured the contextualized interpretations of agents and their actions (Mason, 2002; Miles and Huberman, 1994, p.56). Our data analysis helped us understand how certain groups converged or differed in their interpretations. For example, we saw a clear pattern between the interpretations of the 'reform' group and those of the 'target' populations $^{\text {ix }}$. Our final analysis involved converting all data relating to contextual conditions and agents' actions into a deeper and more meaningful theoretical narrative (Miles and Huberman, 1994, p.91). In order to do this, we developed a coding scheme that would capture the empirics of the case study (Mason, 2002; Miles and Huberman, 1994, p56). While developing this coding scheme, we had to keep in mind the broad theoretical framework, i.e., critical realism, as well as the substantive theory of regressive reforms, i.e., Sieber's theory (1981). For this purpose, we used a coding scheme borrowed from Strauss (1987). According to Strauss (1987), a researcher should start with a coding scheme that differentiates between 'conditions', 'interactions among actors', 'strategies', and 'outcomes'. The benefit of this coding scheme is that it fits in very neatly with the tenets of critical realism, which analytically categorise the flow of social action into structural conditions and agents' actions that cause outcomes. The next two codes, i.e., '(inter)action amongst actors' and 'strategies' helped us see the relevance of Sieber's (1981) coding mechanisms to the different strategies and actions of agents. The last coding scheme, i.e., outcomes, would capture the regressive effects.

As we analysed the data, we constantly reworked our coding scheme to capture the nuances of the data and to theorize the process of conditions, (re)actions, strategies, and outcomes. For example, during our data analysis, we realised that there were 'outcomes' in the form of regressive effects that also proved to be the 'conditions' for causing the next cycle of actions, leading to further regressive effects later on. 
Therefore, we coded some empirical outcomes as 'outcomes' as well as 'conditions'. As a final step, we re-checked the consistency between the data sources, the data codes, and the theoretical conclusions we had drawn. The result of our analysis is presented below in the form of a narrative that describes the structural conditions, the actions and strategies of agents, and their regressive outcome as depicted in Figure One.

\section{Structural Conditions (SC1)}

The first stage of our processual model, i.e., structural conditions 1 ( $\mathrm{SC} 1$ ), helps us understand the structural conditions that surrounded the reforms agents and target population, which provided them with material and ideal (cultural) interests to prescribe (for reform agents) specific cost saving reforms and resist them (for target population). The case organisation, CAA, was formed in 1982 to run aviation affairs (regulation, air traffic control) as well as to manage the airports. While the entity was under the administrative control of the Ministry of Defence, Pakistan Air Force (PAF) was in charge of running the organisation. From the inception of the organisation up until 2006, almost all the Director Generals of CAA were from PAF. Pakistan's political history is important to understand the influence of PAF over CAA as military dominance is the rule rather than the exception in the Pakistani state. Since the inception of the Pakistani state in 1947, the military has held the power for most of its history. Military governments enacted laws creating mandatory quotas for the appointment of military officials in civilian organisations, which resulted in the expansion of military's influence across the state, civil society, and the economy, including the case organisation, CAA (Ahmad, 2004).

After independence, Pakistan, like many other post-colonial countries, went through phases of industrialisation (1950s and 1960s), nationalisation (1970s), and privatisation (1980s onwards) (Hopper et al., 2009). In terms of the management of public sector organisations, the country suffered from all the issues that are the hallmark of less developed countries, i.e., bad governance, corruption, politicization, and inefficiency (Allawattage et al., 2007). In order to cover fiscal deficit, Pakistan had been borrowing 
heavily from international lending and development institutions. This continuous dependence on borrowing meant that Pakistan had to comply, or appear to comply, with the demands of international financial and development agencies. A constant demand had been to privatise or to otherwise improve the governance of public sector organizations, most of which were suffering heavy losses and were subsidized by the national exchequer. When General Musharraf, the last military dictator, took control of the government in 1999, he appointed a renowned Pakistani banker, Shaukat Aziz, working at Citibank in the US as the finance minister of the country in order to address Pakistan's economic problems. The finance minister was generally appreciated by local and international media for his efforts to reform the economy (Idris, 2004).

After taking charge of the Ministry of Finance, the ex-banker introduced a series of initiatives to run the state bodies on modern lines. For example, efforts were made to improve financial accounting and reporting of state ministries and departments through a World Bank funded project by the name of PIFRA $^{x}$. In 2003, a modern medium term budgeting framework (MTBF) was introduced to eventually replace the traditional budgeting system. MTBF was supposed to have a longer planning horizon (3 years) with resource allocations decisions linked with programs and outputs. All these efforts were aimed at making the public sector more economically efficient.

After becoming the prime minister of the country in 2004, he enhanced his efforts to bring the corporate sector ideals of economic efficiency in the public sector. For example, addressing his first cabinet meeting, the prime minister said:

The new cabinet will be result-oriented and not activity driven. Performance of the cabinet will be judged by what it achieves and delivers to the people... Efficient management is the key to good governance, and that is what I expect from my cabinet colleagues ... [Each minister] will prepare quantifiable goals and targets. From the[se] goals and targets will emerge the vision of 
government, which he will share with the people... These tasks and targets will be reviewed on a quarterly basis (Daily Fronteir Star, 2004).

It was clear from various public statements and reported news that the prime minister wanted the state and its various entities to have clearly identified means-ends relations like the private corporate sector as conventionally portrayed in text books. To this end, the prime minister decided to appoint 'successful' corporate managers as the chief executives of public sector organisations. The appointment of FR (pseudonym), a former national manager of a large multinational firm, as the Director General (DG - the top executive post) of CAA was a similar step.

In August 2006, FR was given a two-year contract to carry out the necessary reforms. FR (the new DG), in his interview with one of the authors, stated that the prime minister was unhappy with the way public sector organisations were managed and thought that people like FR should come forward to serve the country. This clearly indicates the trust the prime minister placed in FR's capabilities as a 'manager'. According to FR, he accepted the position at CAA with the sole intention of 'serving the country' by making CAA even more profitable and transforming it into a 'business-like enterprise'. Immediately after his appointment, he formed a 'change team' comprising young officers who had degrees in business or related fields from reputable local or international schools led by a senior manager. New appointments were also made at the senior level in finance and HR with private sector managerial backgrounds. This was justified on the grounds that existing senior management within the organisation was well endowed with technical expertise but lacked private sector 'managerial' experience. Reform agents in this case thus include the prime minister, FR, the change team, and newly appointed managers of business background within CAA.

In critical realist terms, this structural context provides the position-holders, for example, the prime minister, with material interests to comply or appear to comply with conditions of international financial and development institutions to continue to get their financial support. Good governance in terms of the 
economic efficiency of state institutions is one such condition. Similarly, the circumstances of FR's appointment as the executive head of CAA were such that he had to introduce changes in the organisation immediately. The change team was given a mandate by the new DG to bring about a change towards making the organisation more economically efficient. The pressure to remain in the circle of power means that young officers in organisations have to do their best to 'please' the top man (Jackall, 1989; p.24). It is important to note that Jackall (1989) is describing the pressures that are related to the positions of confidants of the Chief Executive and is independent of the individuals occupying those positions. In the case of CAA, the structural pressures in which all change agents were enmeshed meant that some effort to bring about economic efficiency was necessary. In addition, all change agents felt compelled to move quickly because the 'two-year' clock (DG's contract) had started to tick. It was not just the case of material structures giving the reform agents, reasons to bring about corporate style changes within this public sector organisation. The cultural conditions shaped by their history, academic and professional background and experiences also pushed the reforms agents in the similar direction.

According to reform agents, many aspects of CAA's affairs required change. For example, the basic strategic stance of CAA favoured the protection of the national airline (PIA) rather than promoting competition between airlines, and this, according to the reform agents, was not in accordance with the spirit of modern day market mechanisms. Similarly, many aspects of the organizational structure and the practices were 'outdated'. Most importantly, all reform agents believed in the principle of 'profit maximization'. One key reform agent (not a member of change team), for example commented in his interview with us: "Yes, it (CAA) is profitable, but it can become much more profitable . . For an organization to become dynamic and vibrant, its financial muscle should be strong" The change team also subscribed to the same ideas. The fact that almost all members of the change team had recently done their (executive) MBA's was also a factor that was shaping their 'ideal interests'. According to one member of the team, "We had read the concept of 'dynamic organisation' in our MBA . . To us; this was an opportunity to convert this typical public sector entity into a dynamic organization." As explained 
earlier, structural conditions including both material and cultural conditions provide the agents (incumbents of positions) with reasons to act in a certain manner.

As far as the target population was concerned, the material conditions did not provide them with any reasons to support the cost control initiative. Given CAA's financial performance over the years, senior managers did not see any reasons to bring the costs down. At the same time, there was evidence of cultural conditions that may have 'pushed' them to resist cost control reforms. Firstly, almost all respondents, with the exception of the change team, would take a lot of pride in the fact that their organisation was a profitable public sector organisation and as such needed no 'cost management' reforms. A senior manager opined: "If prime minister worries about profitability, he should have focused on literally thousands of loss-making entities ... that is where his (FR's) business skills could have been tested better!" Given the fact that financial surplus in public sector organizations is a rare thing in Pakistan (Zaidi, 1999), CAA managers and employees would consider this to be a huge achievement on their part. The idea of cost management reforms within their organization ran contrary to what they believed was their major achievement. Looking at the revenue and cost structure of the organization, one could argue that this profitability might have something to do with the monopoly status of CAA and the geographical location of Pakistan, which makes it a preferred choice for international airlines to use its air space for certain routes (CAA Business Plan, 2007)). However, a vast majority of CAA employees that we interviewed or interacted with did not 'see' it that way.

Secondly, almost all employees that we interviewed considered a guaranteed job as a 'right' of public sector employees. Any cost cutting effort that involved employees' lay off was thus considered to be a violation of that 'right', a right guaranteed to them by the employer at the time of their employment. One CAA manager working on a large international airport commented: "When they were young, they chose lower salaries but a guaranteed job. If they wanted to, they could have opted for a private sector job which promised higher salary but no job guarantee. They didn't opt for it back then. Now you cannot go back on your word". 
Lastly, there seemed to be an unwritten 'code' in the CAA that functional heads (termed in the CAA as directors) were supposed to be 'protectors' of employees in their function (directorate) against any 'foreign excesses'. They could punish the employees working for them but they had to protect them from others. If a director could not do so, he was considered a weakling and a dishonourable leader. For example, one director while talking about another director said: "His man got caught in the radar inquiry case......[H]e should have protected him from them (the inquiry commission).... could have punished him on his own later.....he's a weak director" To some extent, this could be a function of the tribal society ethos of the country within which CAA managers operated. According to these ideals, 'elders' are given a lot of respect; but in return, are expected to show kindness and generosity towards the 'young' (Ansari and Bell, 1991). In CAA, these ideals about protection of juniors were reflected in stories that our interview respondents shared with us.

Structural conditions described above helped us in understanding different and divergent material and cultural interests within which the two set of agents (i.e. the reform agents and the target population) were enmeshed. At the same time, they also helped us in understanding the agential actions presented below.

\section{Rush for Reforms by the change agents (A1)}

Our analysis reveals that the need for economic efficiency and its rushed nature were somewhat intertwined and both were linked with the structural conditions in which FR, the change team and all other reform agents came onto the scene. The 'interests' and 'positions' of the reform agents meant that they had to strive to improve the profitability of the organisation, and this had to be done swiftly. The question was, how swiftly should it be done and how should the change wheel be set in motion? This is the domain of agency, where agents reflect on the situation, draw on their past experiences and devise strategies (Archer, 2003).

While there was a structural push towards the need and speed for change, the question regarding 'agential' significance was, 'what would be the pace of change'? In the case of CAA, change agents, 
specifically FR, just rushed to implement change. This rush for change could be judged from the fact that it took FR only around 24 days (from the date of appointment) to constitute a change team (see Table 1).

\section{[Insert Table One]}

This rushed change was also a function of FR's prior 'understanding' of public sector organisations. He reflected: "I had known the way public sector organizations work from my days at [XXX]. Most of the public sector organizations are standing still. [These] have not changed with time at all. Everything is lying still there". The change team also worked very quickly in identifying the changes required. As one member of the team commented in his interview: [Our team leader] gave each of us the responsibility for examining the roles of CAAs in different parts of the world. We spent around five to six days studying the functioning of CAAs in different countries. Official records reveal that in early October, the change team members, after studying 'international best practices', had started developing their initial plans. Simultaneously, plans for 'selling' the change to the senior managers of CAA were also being devised by FR and the change team. For this purpose, consultants were appointed from among faculty members in the top business school in the country to conduct a vision exercise. Official records indicate that, in total, there were three meetings between the change team and the consultants, including one at which FR was also present. Afterwards, the consultants were flown to Karachi, where they held a quick round of meetings with the senior managers. This 'quick and dirty cultural audit', as one consultant put it, was deemed sufficient for them to run the vision exercise. The exercise was conducted by the consultants in conjunction with the entire senior management and selected mid-level managers. In the vision exercise, it was clearly stressed that CAA needed to be 'modernised'. The vision exercise was quickly followed by meetings with senior managers where the plans for change had to be crystallised.

\section{'Lean and Mean' Organization: Provocation and Resistance (A2)}

We find the evidence of provocation, one of Sieber's mechanisms, which caused the target population to mount resistance against reforms. Provocation refers to reform efforts that are perceived by the target 
population as threatening, resulting in the target population taking collective action to thwart the reform efforts in a way that leads to further deterioration of the conditions that the reforms are intended to address. We also need to understand why the provocation was employed drawing from underlying structural conditions. The need for economic efficiency or greater organisational profit was a structural pressure felt by the 'reform team'. However, the question was, which strategy would they adopt to achieve this goal? They chose to rationalise the number of managerial positions to reduce the most significant expense item - salary expenses (approx. $80 \%$ of the total annual expenses). Traditionally, the primary instrument of cost management at CAA was budgeting. The primary reference point for preparing the budget or for its accuracy was always the previous year's expenses. The DG, along with other members of the budget executive committee, would approve the draft budget, which was then presented to the Board of CAA for final approval. While the budgeting system provided a reasonable defence against unnecessary increases in costs, it did not provide any mechanism for reducing costs below the existing level, which was what the change team wanted at that stage.

It is important to note here that there was no systematic study carried out to determine if there was a need to rationalise these positions. It was more a question of the 'feelings' of the reform agents based on their knowledge about the public sector in Pakistan in general and CAA in particular. For example, immediately after FR took charge of the organisation, he went to visit different operational sites, i.e., airports. In his interview, FR commented, "I have a habit that whenever I go on an airport visit, I'll just go around and visit various administrative offices. Soon after my appointment, I went on a visit of various airports. At each airport, I randomly opened any office door and inside, I would find loads of people sitting absolutely idle." Given their academic background, most change team members believed in the concept of a 'lean and mean' organisation and thought that the excessive 'fat' should be cut.

In addition, some members of the change team were very vocal about the need for change in the organisation. They tended to express this change in their informal meetings and gatherings as well as in official memos. The newly appointed DG and his connection with the prime minister gave them a certain 
confidence to express their feelings openly. Open expressions about overstaffing in CAA of the reform agents further created a sense of fear and suspicion about reforms among the target population. To them, it was a blatant act of provocation by the change team. According to one CAA employee, " $D G$ 's popularity amongst employees when he joined was zero. He was assumed to be a person who had come with an agenda of downsizing [...] the organization." On describing how strain first appeared in the relationship between DG and employees, one employee said:

After joining as DG, he visited various airports. The first thing that he said when he visited, for example, Lahore Airport was, 'Oh my God, so many employees...much more than we need.' Then he, for example, went to Faisalabad Airport, and we would call Faisalabad to ask, 'What did he say there?' and they would say, 'He said, 'Too many employees!' and we would say, 'He said the same here'. So, when he went to Islamabad, those guys already knew what DG had said at the previous two stations - that there were far too many employees than we needed. You know, we talk a lot with each other! So, in a sense, his reputation would reach the next airport before him! So, when he said the same thing at Islamabad and at other airports that he visited, a consensus started emerging amongst employees that he was after downsizing. Employees had no trust in him whatsoever. They started looking with suspicion at every action that he took.

Not surprisingly, the vision exercise, which was carried out to 'sell' change to managers, did not have the desired results, but instead exacerbated the atmosphere of mistrust and suspicion. For example, describing the vision exercise, one manager reflected:

The vision exercise was a show, to try to implement the change suggested by [management]. I mean, they should have been open about it... I mean, do they consider us fools? [...] You see, they were influencing the whole process. They would, for example, come into a discussion 
room, and if we had written a core value on our discussion board, they would say, 'I wouldn't call it my core value'. I mean, what is this?

Immediately after the vision exercise, the change team presented to the directors (heads of the directorate) their estimation of the number of senior managerial positions required to run the organisation in a cost effective manner. Impressed by the principles of 'lean management', the change team proposed that the number of senior-level positions should be cut substantially. While cost management was a structural pressure, why did the change team choose to start with rationalising the senior management positions? The change team response was that "CAA was too top-heavy an organization." Trimming the positions at the top, in their assessment, would cut down on costs and make the organisation structure more balanced.

This proposal did not go down well with senior management of CAA. However, in this extremely hostile environment, open resistance in terms of rejecting the change program early on was difficult for the target population (Ezzamel and Burns, 2005). After all, the change programme was initiated by the new DG, who was the executive head of the corporation; had immense powers to punish or reward them (the target population). At the same time, the new DG was known to be a close friend of the prime minister of the country. For all they knew, the new DG had been brought in by the prime minister to bring about changes in the organization. The change programme thus had the blessings of none other than the prime minister of the country. Senior managers of CAA thus decided to take a 'subtle' approach (Scott, 1985; Hodson, 1995).

The senior managers present at the meeting unanimously disagreed with the proposal. They claimed to have a better idea of the functional requirements of their respective directorates and, on the basis of this 'knowledge', rejected the numbers presented by the change team. Senior managers 'strategically' objected only on the process by which the number of positions had been determined instead of the change agenda itself. The change team was not in favour of listening to them. They believed that they had worked out the number of required positions in an objective fashion. A member of change team pointed out: 
"They started raising questions and concerns in that meeting. We had satisfactory answers to all their questions. We did try and respond to their comments but FR told us to just listen and note down their arguments." After listening to all the concerns of senior managers, it was decided by FR that the HR department would work with the respective directors to determine the number of senior level positions required within each directorate. After all a better knowledge of the directorates (especially, technically complex directorates) was a claim made by the directors which could not be easily rejected.

In the ensuing 'negotiations' between the HR department and the directors, the latter made full use of their 'expert knowledge' to claim as many positions for their respective directorates as possible. A few months prior to the reform period, Pakistan International Airlines (PIA) was temporarily banned from flying to Europe and the US due to the shambolic record of repair and maintenance of its aircraft. This had caused a major loss to the exchequer and to Pakistan's national reputation. This issue was highlighted for many days in the national media and created considerable embarrassment for the federal government. In negotiations between the HR department and the different regulatory directorates, the latter took full advantage of this incident, claiming that the number of senior level positions needed to be increased substantially to ensure that such embarrassment do not recur. The Directorate of Regulation thus asked for 20 more positions to carry out impromptu inspections. This increased number of inspectors, according to the Directorate's senior management, was essential for ensuring compliance with aircraft safety regulations. It was extremely difficult for HR to reject the claims by the directors especially when the issue of public safety was involved.

\section{Regressive Outcome 1 (RO1): Placation}

Placation is another mechanism that produces regressive consequences. Sieber (1981) refers to placation as the kind of reforms that are meant only to placate the target population while serious reform was never the intent, resulting in a situation deteriorating further. Another possibility through which placation can cause regressive results is the eventual realisation by the target population of the 'reality' of the reforms. 
This can cause them to become angry, leading to further deterioration of the situation. In case of CAA, placation seemed to emerge as a result of resistance put forward by the target population.

After deliberations between the directors and the HR department, the number of senior management positions required for each directorate was finalised. This number, however, was quite disturbing for the change team. CAA had a permitted number of 87 general manager positions (number '2' position in every functional area), which had been cut to 52 by the change team in their original proposal. Likewise, the 18 director-level positions (number ' 1 ' position in each functional area) had been cut to 12 . To the utter dismay of the change team, the organisational plan agreed upon between HR and the senior managers consisted of 129 general manager positions and 23 director positions. Some directorates received more benefits than did others depending upon the 'technical' nature of their job and perhaps the articulacy of the director.

Although this outcome was contrary to the very spirit of the change programme that the change team desired to implement, rejecting this outcome would have meant that the change programme would not have had the support of the senior managers at CAA. This was again a moment of agency. Not all reform agents were unanimous in their views about this. The majority of members of the change team were not in favour of acceding to these demands. Reform agents could have forced the issue and gone to the Ministry of Defence for approval of the change plan without the expressed consent of the senior managers at CAA. However, the question was, which strategy would they adopt to achieve this goal? At the time, some key reform agents, including at least one member of the change team thought this would have weakened their chances for getting approval for other crucial aspects of change program planned from the Ministry. In addition, it was the start of the change process, and there were many battles to fight in the future. Keeping all these factors in mind, they decided to placate the senior managers by agreeing to the proposal to increase the number of top-level positions within different directorates. 
The result of the provocation, resistance, and eventual placation was that the number of senior management positions actually increased, a regressive consequence of the reform originally aimed at reducing these numbers. This outcome also marked the end of one cycle of initial structural conditions, agents' actions, and strategies and outcomes (Archer, 1995). In line with realist thinking, this outcome also provided the conditioning effects for the next cycle of social actions by providing agents with tendencies to act in a certain manner (Sayer, 1992; Archer, 1995).

\section{Conditional effects of regressive outcome 1: Reciprocal classifications and exploitation (A3)}

Compromise and the regressive effect created its own set of conditioning effects. While there was already a trust gap between the reform agents and the target population, the regressive outcome widened it considerably leading to labelling and exploitation, two mechanisms that can also cause regressive results (Sieber, 1981). We found clear evidence of reciprocal classifications and allegations of exploitation at CAA. Classification means labelling the target agents in a certain way or otherwise dividing them into categories. While this labelling intended for customised reforms, this often creates stigmatizing effects on the target group leading to regressive consequences. By exploitation Sieber (1981) refers to a mechanism whereby the reform agents or the target population use the reforms as a cover for the attainment of their personal benefit. There can potentially be nothing wrong with the reforms as such, but the change team or target population subvert these reforms for their private gain, thus rendering the situation worse than before. In case of CAA, we observe 'reciprocal classifications', where both groups labelled each other as 'exploiters', the details of which are following.

To the reform agents, the compromise and the regressive results marked a victory for those who did not want change. The reform agents believed that there were two specific reasons why some members of the target population rejected change. These reasons included first, the ignorance of target managers about modern ways of managing organizations. For reform agents, the target population were frozen in the past people, who knew nothing more than their typical 'public sector style' of working. 'They are so ignorant 
that if you give them a rose with a long stem, they wouldn't even know what it symbolizes?' claimed one reform agent. In their day-to-day discussions, the reform group often referred to the target population as 'dead-wood'. This classification of the target population as 'dead-wood' was so frequent that the same term was used for some CAA managers within a report made by a special committee formed by the prime minister on public sector reforms. Not surprisingly, FR was a member of this special committee.

From the reform agents' point of view, the second reason due to which the target population was resisting reforms was their 'vested interests'. According to our interviews with a number of reform agents, the target population (i.e., senior managers within CAA) wanted to protect and expand their respective 'empires'. The bigger the directorate, the more influential the directors would be. For reform agents, this vested interest of directors of CAA prevented them from supporting the cost management reform.

The target population also labelled the cost management reform as a mere eye-wash, where the 'true' intent of the reform agents was to acquire the control of the organizational affairs. At the same time, the target population also believed that the reform agents were 'ignorant' about the intricacies of a complex public sector aviation entity. In our interviews, some members of the target population shared that CAA was a multifaceted public sector entity; and reform agents had no working or theoretical knowledge about it. They believed that reform agents were seeing this complex organisation through a simple prism of profit maximisation. "We are not in the business of selling oil....you sell oil and make profit, simple", said one CAA manager to us in his interview. As explained earlier, FR was the former country head of a large multinational oil-marketing firm. In order to emphasise his lack of aviation knowledge, FR was commonly referred to by the CAA managers in a derogatory manner as an 'oil seller'.

Thus both groups accused each other of being 'ignorant' and exploiting the cost management reforms to serve their vested interests. An increase in the number of positions worsened the relationship between two groups. The regressive outcome created a conditioning effect that caused the reform agents to become hostile towards the target population. It was decided that any further 'resistance' had to be handled 
severely. During the course of the fieldwork, while one of the authors was collecting data, the change team members were sharing the same sentiment, not only during their interviews but also during informal chats between change team members in the presence of the author. A member of the change team said in his interview: "There are many directors who do not want change [...] We 'll now take them head on." Similarly, on another occasion, FR wrote a memo threatening that those opposing change would be dealt with severely.

\section{Regressive Outcome 2 (RO2): Functional Imbalance}

Functional imbalance refers to a situation where the reform agents focus too much on one aspect of the organization, ignoring others, resulting in creating a functional imbalance (Sieber, 1981). This functional imbalance in turn produces regressive results. This is exactly what happened in CAA. Against the backdrop of such suspicion and hostility and a few months into the change program, the Director of Air Traffic Control sought more traffic controller positions. This was seen by the change team as another move to make the organization less cost efficient, and hence they paid it no heed. In order to strengthen their case, the air traffic control department conducted a 'work load study' to determine the exact number of air traffic controllers required. The study 'revealed' that there should be a significant increase in the number of air traffic controller positions. A senior official of Air Traffic Control Directorate said, “My men need rest... Air traffic control is a very stressful job... According to International Civil Association Organisation standards (ICAO), they need to be given rest after two hours of active duty.... They are handling around 700 movements per day. We didn't get any positions last time..." While it was difficult to verify their claims, there was no doubt that air traffic had increased tremendously during the years 2007 and 2008.

Evidence to support this claim could be seen in the increased aviation revenue figures appearing in CAA's financial statements; in the first two years of FR's term, the annual reports showed there had been a $17 \%$ increase in aviation revenue. This was mainly due to the increasing number of flights operated in 
Pakistan and the surrounding area, which would suggest that the workload must have increased. However, had it reached a point where it was essential to hire more air traffic control staff? The senior managers of the Air Traffic Control Directorate thought so, but the reform agents thought otherwise. The demand for increased air traffic controller positions was rejected outright by the change team. In fact, it was rumoured in the organisation that on hearing the demand, the new DG stated categorically that no further positions would be created while he was in CAA.

During our interviews with some of the reform agents at the time, they dismissed the demand as an unnecessary economic burden and claimed that there were already enough people working for the Directorate of Air Traffic Control. It is important to note that increased aviation revenues meant that organizational profitability had already gone up. However, cost management was seen by the change team as an independent activity that would cause the profits to go up even further. However, it transpired that refusing to create extra air traffic control positions created a functional imbalance, resulting in a number of life threatening situations for passengers. Notably, there was a significant increase in the number of 'air misses $^{\text {,xi }}$ in Pakistan's air space since the cost management reforms began in 2007 (Khan, 2008). An inquiry report conducted by the Safety Board of the CAA revealed that the annual number of air misses had risen to 20 in the year 2007, whereas the same number in the previous year had been fewer than 3, a number that, importantly, was within the acceptable limits of aviation safety standards ${ }^{\mathrm{xii}}$. According to the inquiry report, this alarmingly unsafe air traffic situation was due to understaffing and overwork. The inquiry report stated, "This steep rise of ['air miss'] incidents in 2007 is due to an increase in over flying traffic, which has almost doubled over a period of 2-3 years. ... At the time of [a particular air miss] incident, the air traffic controller had some 16 aircraft under his control and he exchanged about 120 radio calls with them over a period of 15 minutes. He had performed over seven hours of continuous duty, thus losing his concentration due to fatigue."

The functional imbalance created through the rejection of the demand by the Directorate of Air Traffic Control had led to the second regressive outcome and had given rise to life-threatening situations. Forty 
serving and retired officials from PAF were immediately hired in senior positions to serve as air traffic controllers at different locations within CAA. This also meant that the number of managerial positions rose even higher. The outcome in the form of a regressive outcome weakened the position of the change team and strengthened the target population's position. In a way, it validated their superior knowledge about the affairs of the case organisation. This strengthening of the positions of respective groups of agents would undoubtedly have a bearing on next cycle of social actions (Archer, 1995).

\section{Discussion and Concluding Remarks}

The paper aims to provide a wider explanation of regressive effects' of management accounting and control reforms in a less developed country such as Pakistan. As the literature indicated, not all NPM reforms fail; and even if they do, their extent of failure and the reasons for failure may differ from one case to the next (Pollitt and Bouckaert, 2011). Given this, we believe developing a theoretical understanding of such failures is important for both academics and policy makers. We have presented a case of regressive effects of cost management reforms using Sieber's (1981) mechanisms complemented with the deeper understanding of structural constraints and agential actions drawing from critical realism. An important link that the theoretical framework puts forward is that one regressive outcome in a reform can itself act as a condition for another regressive outcome. The processual model proposed in the paper articulates the complex relationships between structural conditions and agents' actions that encompass the functioning and interaction of multiple regressive mechanisms ${ }^{\text {xiii }}$, i.e., provocation, classification, placation, exploitation, and functional disruption (Sieber, 1981). We first discussed how structural conditions (material and cultural) in Pakistan influenced key agents and how agents in turn reflected on pressures and took actions (change and resistance). This enabled us to explain multiple mechanisms which appears to contribute to the regressive consequences of reforms at CAA.

Our analysis, as depicted in Figure 1, suggests that the structural conditions as well as agents' strategies/actions led to regressive outcomes. At CAA, the structural conditions (SC1) included the 
financial dependence of the country on international lending agencies. This dependence is critical for country's financial liquidity. This in turn means that prime ministers of countries like Pakistan cannot ignore the reforms demanded from international lending agencies. Legitimacy of the military backed governments from the Western countries and institutions are crucial as demonstrated in previous studies (Uddin and Hopper, 2001). The appointment of a banker, as the prime minister of the country, and of a private sector business manager, as the executive head of a corporation needs to be seen in this structural context. It is clear that reform agents at CAA have material interests to bring about change as their appointments are linked with the reforms. We contend that it is not just material conditions that 'pushed' the reform agents towards cost management reforms (Archer, 1995). The cultural conditions engendering these ideals were linked with the professional and educational background of these 'reform agents', including FR, the 'change team' and the newly hired business managers. For example, FR was not just the director general of the CAA, he also assumes a subject position of a 'professional business manager'. This identity drawn from his past professional background was perhaps influencing his agency by giving him a sense of 'what was CAA': an inefficient, overstaffed, and frozen in time, public sector organisation.

In contrast, senior managers' material conditions did not provide them with any motivation to support cost management reforms. At the same time, their cultural conditions enabled them to 'see' reforms in a certain way, including their moral validity. For instance, senior managers had a strong belief that CAA was a 'profitable public sector organisation'. Any cost management reforms thus ran contrary to their beliefs about the financial prudence with which the organisation, in their opinion, had been run so far. The 'unwritten code' that suggests that directors should 'protect' their men and that life-time employment is an unwritten contract with all public sector employees were providing the directors with ideal interests to resist the cost management reforms, especially because the reforms involved were aimed at cutting down managerial positions.

Critical realist theory argues that while structural conditions 'push' agents in a certain direction, the pressure is not 'hydraulic'. The agents subjectively weigh structural conditions in the light of the future 
projects that agents chose for themselves, past experiences and the practical feel for the situation at hand (Archer, 1995, 2003). For example, in this case, FR just 'knew' from his past experience of dealing with public sector organisations about the 'problems' that public sector organisations face including overstaffing. This can partially explain why the pace for change was so fast, as any 'diagnosis' was perhaps considered unnecessary. Agents have to 'read' the situation at hand, in the light of their past experiences, which provide them with tools for such reading in the form of 'categories' or 'schemas' (Schutz, 1962; p 75). At CAA, for instance, the type of change (rationalising the number of positions for cost management), and the manner of change (e.g., openly expressing the view that there were too many people working in the organisation) were the reflective strategies of the agents.

Clearly, provocations such as open expression of over staffing were intensely disliked by senior managers. Nevertheless, senior managers had to take a strategy of subtle resistance. The strategy of subtle resistance was a reflection of their 'readings' of the present situation, their fears associated with following different courses of actions, as well as past experience and future projections. This strategy proved 'successful', causing the reform agents to eventually decide to retract and placate the target group thus creating initial regressive effects. It is important to stress here that agents which find themselves in similar structural conditions may differ in terms of their 'reading' of the situation at hand or their future projections about the outcomes associated with different decision choices. For example, while most members of the change team were not in favour of giving in to demands of senior managers of CAA, FR decided to accede to their demands to placate senior managers. This reflects the subjective nature of agency. As a result, the positions of senior managers were considerably increased.

It is also important to understand that interpretations of structural pressures are not rational means-ends calculations carried out by emotionless agents. These agents are individuals who assign subjective price tags to different courses of action (Archer, 1995) in real life situations including price for 'ends' that they value for being, for example, 'directors of CAA' or a 'business oriented director general' of CAA. There is every possibility that agents will commit a 'mistake' in interpreting these conditions or regarding the 
possible consequences of their actions. In our case, the open expression of the need for change provoked the target population, which was probably not the intention of the change group. At any rate, initial regressive effects created its own set of structural conditions causing both groups to 'label' each other as 'exploiters' working in their respective vested interests; and 'ignorant', not aware of how a modern organisation or a public sector organisation should be run. As a result of the conditioning effects of the first regressive outcome and the subsequent actions of the target population, the reform agents vowed not to compromise again, eventually leading to functional imbalance. The functional imbalance was created because the demand of more air traffic control positions was denied by reform agents on account of cost management, leading to serious air safety risks, eventually causing more air traffic controllers to be hired by the organisation, thus causing a second regressive outcome.

The critical realist's interpretations of structural conditioning and agential reflections, we would argue, provided deeper explanations of why regressive mechanisms, such as placation, provocation, labelling/classification, exploitation, and functional imbalance might have occurred at CAA. Overall, the processual model developed in the paper has enabled us to understand the rushed and aggressive nature of the cost control reforms that 'provoked' the target population was a function of the structural pressure being faced by the change team. While the pace of the change could perhaps have been a little slower, it is clear that the structural conditions forced the agents to move more quickly. Similarly, the strategy of placation that the change team adopted was not so much an attempt to please the target population as a kind of compromise that the change team believed was necessary in the situation. Thus, the regressive effects that we encountered in our case study were the effects of structures in which agents were enmeshed as much as they were the actions/strategies of the agents on the scene.

We believe that the paper makes important theoretical and empirical contributions. First, in the process of engaging the empirics of our case study and critical realism with Sieber's work, this paper contributes to Sieber's (1981) theory of regressive effects. Sieber (1981) developed his theory with the objective that once we understand the reasons for regressive reforms, we can overcome these unwanted outcomes by not 
committing those actions (Sieber, 1981; p.204). By incorporating structural conditions and agential reflections into our theoretical landscape, our case study problematizes such linear explanations. One can argue that in less developed countries, material conditions, necessitating cost management reforms will be similar. However, cultural conditions influencing the agents may be unique, not just for each country, but also for individual organisations within the same country (Guthrie et al., 1999; Pollitt and Bouckaert, 2011). In case of CAA, cultural conditions provided the agents with identities which are unique, creating action orientations which went against reforms: directors as 'protectors' of employees working in their respective directorates or CAA being a 'profitable' organisation were two such examples. Appreciation of these unique cultural conditions is a key to better understanding and theorization of management control reforms in less developed countries.

Second, the paper contributes to management accounting changes in the context of NPM and wider structural adjustment programmes. While we do not wish to claim that the processual model will be applicable to all NPM-related cost management reforms, nevertheless, regressive outcomes are always a possibility, especially in the structural conditions where many public sector organisations operate in less developed countries. Previous studies have demonstrated similar structural conditions for NPM in poorer countries (Allawattagee et al., 2007; Hopper et al., 2009). In many of these cases, NPM reforms are brought about by private sector ideals of cost management and are championed by private sector change agents (Wickramasinghe and Hopper, 2005). It is also not uncommon that change agents are pressed for time or want to implement such changes quickly (Wickramasinghe et al., 2004). Such structural conditions can create a chain of agents' actions and reactions where the regressive outcomes described in our theoretical model can become a real possibility. NPM researchers have already highlighted such risks by warning that, unlike developed countries, less developed countries often do not have a strong history of public service ethics capital (Hood, 1991). This exposes them to greater risks of functional imbalance and other regressive consequences. There is no denying that if there is any chance of controlling undesirable social outcomes, it is by understanding their underlying causes. One of the biggest 
advantages of analysing an empirical situation through a critical realist research tradition is that it helps us understand such causes. This perhaps, one might argue, opens up space for better policy making (Broadbent and Guthrie, 2008; van Helden and Northcott, 2010)

Third, previous studies predominantly have focused on the unintended consequences of 'reforms'. This paper draws attention to one particular form of unintended reform effect, i.e., the phenomenon of 'regressive effects' of management accounting and control reforms in a less developed country. Also, this paper particularly scrutinizes the 'cost management' reforms which, surprisingly, have received little attention in public sector management accounting research (van Helden, 2005). Despite the issue of economy vs. effectiveness at the heart of the NPM debate, extant public sector management accounting research has not addressed the role of cost management efforts in sufficient detail (ibid; Hood, 1991). In our case, the significant rise in the number of air misses is undoubtedly linked with the desire to control costs on the part of reform agents. Clearly, cost management efforts at CAA went wrong both in terms of effectiveness and efficiency. Nevertheless, the processual model shows that the link between the desires of reform agents to bring about cost management reforms and the eventual outcome in terms of increased cost or serious safety hazards is complex. According to the central tenets of critical realism, before intentions come structural conditions that shape the former. To the extent that NPM reforms shape the ideal conditions surrounding public sector managers of favoring efficiency over effectiveness, these reforms are justifiably criticized in the accounting and management literature (Lapsley, 2009).

Finally, it would be useful to examine the contextual differences on NPM reforms and their consequences (regressive or otherwise). One aspect of these differences may be the extent of influence of multilateral agencies on state machines/policy making of both less developed and developed economies. For instance, recent reform package by EU on Greek economy might be an interesting site. The processual model developed in the paper could be further advanced drawing on cross-country research. 


\section{References}

Ackroyd, S., \& Fleetwood, S. (2000). Realist Perspectives on Management and Organizations. London, UK: Routledge.

Ahmad, E. (2004). Between Past and Future: Selected Essays on South Asia. Lahore, Pakistan: Oxford University Press.

Alawattage, C., Hopper, T., \& Wickramasinghe, D. (2007). Introduction to management accounting in less developed countries. Journal of Accounting and Organizational Change, 3(3), 183-191.

Alawattage, C., \& Wickramasinghe, D. (2009). Weapons of the weak: subalterns' emancipatory accounting in Ceylon Tea. Accounting, Auditing and Accountability, 22(3), 379-404.

Ansari, S. L., \& Bell, J. (1991). Symbolism, Collectivism and Rationality in Organizational Control. Accounting, Auditing and Accountability Journal, 4(2), 4-27. doi:10.1108/09513579110143119

Archer, M. (1995). Realist Social Theory: The Morphogenetic Approach. Cambridge, England: Cambridge University Press.

Archer, M. (2003). Structure, Agency and the Internal Conversation. Cambridge, England: Cambridge University Press.

Ashraf, M. J., \& Uddin, S. (2013). A Consulting Giant, A Disgruntled Client: Story of a Failed Consulting Assignment to Change Management Controls in a Public Sector Firm. Financial Accountability and Management, 29(02), 186-205. doi:10.1111/faam.12009

Bhaskar, R. (1975-1997). A Realist Theory of Science. London, UK: Verso.

Bhaskar, R. (1979-1998). Possibility of Naturalism. Hassocks, UK: Harvester. 
Broadbent, J., \& Guthrie, J. (2008). Public sector to public services: 20 years of "contextual” accounting research. Accounting, Auditing and Accountability Journal, 21(2), 129-169. doi:10.1108/09513570810854383

Broadbent, J., \& Laughlin, R. (1998). Resisting the "new public management”: Absorption and absorbing groups in schools and GP practices in the UK. Accounting, Auditing and Accountability Journal, 11(4), 403-435. doi:10.1108/09513579810231439

Broadbent, J., Jacobs, K., \& Laughlin, R. (2001). Organisational resistance strategies to unwanted accounting and finance changes: The case of general medical practice in the UK. Accounting, Auditing and Accountability Journal, 14(5), 565-586. doi:10.1108/EUM0000000006263

Daily Frontier Star (2004), Aziz Chairs First Formal Meeting of the New Cabinet. (2004, September 15). Devereux, S., \& Hoddinott, J. (2002). Issues in Data Collection. In Devereux, S. \& Hoddinott, J. (Eds.), Fieldwork in Developing Countries. Boulder, CO: Lynne Rienner.

Diefenbach, T. (2007). The managerialistic ideology of organisational change management. Journal of Change Management, 20(1), 126-144. doi:10.1108/09534810710715324

Emirbayer, M., \& Mische, A. (1998). What is Agency? American Journal of Sociology, 103(4), 9621023.

Ezzamel, M., \& Burns, J. (2005). Professional Competition, Economic Value Added and Management Control Strategies. Organization Studies, 26(5), 755-777. doi:10.1177/0170840605054598

Fleetwood, S., \& Ackroyd, S. (2004). Critical Realist Applications in Organisation and Management Studies. London, UK: Routledge.

Gallhofer, S and Hasslem, J. (1991) The aura of accounting in the context of a crisis: Germany and the first world war' Accounting, Organizations and Society, 16(5), 487-520. doi:10.1016/03613682(91)90039-H 
Guthrie, J., Humphrey, C. and Olson, O. (1999). Debating developments in new public financial management: the limits of global theorising” Financial Accountability \& Management, 15 (3-4), pp. 209-28. doi: 10.1111/1468-0408.00082

Hesse, J., Hood, C., \& Peters, G. (2003). Paradoxes of public sector reform: Soft theory and hard cases. Berlin, Germany: Duncker and Humblot.

Hodson, R. (1995). Worker Resistance: An Underdeveloped Concept in the Sociology of Work. Economic and Industrial Democracy, 16(1), 79-110. doi:10.1177/0143831X9501600104

Hood, C., \& Peters, G. (2004). The Middle Aging of New Public Management: Into the Age of Paradox? Journal of Public Administration Research and Theory, 14(3), 267-282. doi:10.1093/jopart/muh019

Hood, C. (1991). A Public Management for all Seasons? Public Administration, 69(1), 3-19. doi:10.1111/j.1467-9299.1991.tb00779.x

Hood, C. (1998), The Art of the State. Oxford, UK: Clarendon.

Hopper T., Tsamenyi, M., Uddin, S., \& Wickramasinghe, S. (2009). Management accounting in less developed countries: what is known and needs knowing. Accounting, Auditing and Accountability, 22(3), 469-514. doi:10.1108/09513570910945697

Idris, I. (2004, July 1). Business as usual. AlAhram Weekly.

Jackall, R. (1989). Moral Mazes: The World of Corporate Managers. London, UK: Oxford University Press.

Khan, A. (2008, June 23). Country's airspace is becoming increasingly unsafe. The News.

Lapsley, I. (2009). New Public Management: The Cruellest Invention of the Human Spirit? Abacus, 45(1), 1-21.doi:10.1111/j.1467-6281.2009.00275.x 
Laughlin, R., \& Broadbent, J. (1993). Accounting and Law: Partners in the Juridification of the Public Sector in the UK? Critical Perspectives on Accounting, 4(4), 337-368. doi:10.1006/cpac.1993.1019

Laughlin, R., Broadbent, J., Shearn, D., \& Willig-Atherton, H. (1994). Absorbing LMS: The Coping Mechanism of a Small Group. Accounting, Auditing and Accountability Journal, 7(1), 59-85. doi:10.1108/09513579410050407

Leca, B., \& Naccache, P. (2006). A Critical Realist Approach to Institutional Entrepreneurship. Organization, 13(5): 627-651. doi:10.1177/1350508406067007

Llewellyn, S. (2007). Introducing the Agents. Organization Studies, 28(2), 133-153. doi:10.1177/0170840606067993

Mason, J. (2002). Qualitative Researching. London, UK: Sage.

Merton, K. (1936). The unanticipated consequences of purposive social action. American Sociological Review, 1, 894-904.

Miles, M. B., \& Huberman, A. M. (1994). Qualitative Data Analysis: An Expanded Sourcebook. Thousand Oaks, CA: Sage.

Modell, S. (2009). In defence of triangulation: A critical realist approach to mixed methods research in management accounting. Management Accounting Research, 20(3), 208-221. doi:10.1016/j.mar.2009.04.001

Modell, S. (2013). Making Sense of Social Practice: Theoretical Pluralism in Public Sector Accounting Research: A Comment. Financial Accountability and Management, 29(1), 99-110. doi:10.1111/faam.12004 
Modell, S. (2014). Critical Realist Accounting Research: Whence and Whither? CPA Conference, Toronto, Paper Ref.2014-202.

Mutch, A. (2002). Actors and Networks or Agents and Structures: Towards a Realist View of Information Systems. Organization, 9(3), 477-496. doi:10.1177/135050840293013

Mutch, A. (2007). Reflexivity and the Institutional Entrepreneur: A Historical Exploration. Organization Studies, 28(7), 1123-1140. doi:10.1177/0170840607078118

Mutiganda, J.C. (2013). Budgetary governance and accountability in public sector organisations: An institutional and critical realism approach. Critical Perspectives on Accounting, 24(7-8), 518-531. doi:10.1016/j.cpa.2013.08.003

Pollitt C. (2001). Convergence: The Useful Myth? Public Administration, 79(4), 933-947, DOI: $10.1111 / 1467-9299.00287$

Pollitt, C., \& Boukaert, G. (2011). Public Management Reform: A Comparative Analysis - New Public Management, Governance, and the Neo-Weberian State. Oxford, UK: Oxford University Press.

Power, M., \& Laughlin, R. (1992). Critical Theory and Accounting. In Alvesson, M., Wilmott, H. (Eds.), Critical Management Studies (pp. 113-135). London, UK: Sage

Power, M. (1997). The Audit Society. Oxford, UK: Oxford University Press.

Ross J. (1996). Unintended Consequences. St. Paul, MN: Accurate Press.

Sayer, R. A. (1992). Method in Social Science: A Realist Approach (2nd ed.). New York, NY: Taylor \& Francis.

Sayer, R. A. (2000). Realism and Social Science. Thousand Oaks, CA: Sage. 
Schutz, A. (1962). Choosing among projects of action. In Natanson, M. (Ed.). Collected Papers: The Problem of Social Reality (Vol. 1). The Hague, Netherlands: Martinus Nijhoff .

Scott, J.C. (1985). Weapons of the Weak. New Haven, CT: Yale University Press.

Sieber, S. (1981). Fatal Remedies: The Ironies of Social Intervention. New York, NY: Plenum.

Smith, A. (1776). An Inquiry into the Nature and Causes of the Wealth of Nations. Chicago, IL: University of Chicago Press.

Spencer, H. (1946). The Man versus the State. Caldwell, ID: The Caxton Printers.

Stergiou, K., Ashraf, J., \& Uddin, S. (2013). The role of structure and agency in management accounting control change of a family owned firm: A Greek case study. Critical Perspectives on Accounting, 24(1), 62-73. doi:10.1016/j.cpa.2012.09.007

Strauss, A. (1987). Qualitative Analysis for Social Scientists. Cambridge, England: Cambridge University Press.

Strauss, A., \& Corbin, J. (1998). Basics of Qualitative Research: Grounded Theory, Procedures and Techniques. Newbury Park, CA: Sage.

Thornton, P, Ocasio, W and Lounsbury, M. (2012)The Institutional Logics Perspective: A New Approach to Culture, Structure and Process, New York: Oxford University Press

Uddin, S. \& Hopper, T. (2001). A Bangladesh soap opera: privatisation, accounting, and regimes of control in a less developed country. Accounting, Organizations and Society, 26(7-8), 643-672. doi:10.1016/S0361-3682(01)00019-8

Uddin, S. \& Hopper, T. (2003). Accounting for Privatisation in Bangladesh: Testing World Bank Claims. Critical Perspectives on Accounting, 14(7), 739-774. doi:10.1016/S1045-2354(02)00188-0 
Uddin, S., \& Tsamenyi, M. (2005). Public sector reforms and the public interest: A case study of accounting control changes and performance monitoring in a Ghanaian state-owned enterprise. Accounting, Auditing and Accountability Journal, 18(5), 648-674. doi:

$10.1108 / 09513570510620493$

van Helden, G. J., \& Northcott, D. (2010). Examining the Practical Relevance of Public Sector Management Accounting Research. Financial Accountability and Management, 26(2), 213-240. doi:10.1111/j.1468-0408.2010.00499.x

van Helden, G. J. (2005). Researching Public Sector Transformation: The Role of Management Accounting. Financial Accountability \& Management, 21(1), 99-133.

Wickramasinghe, D., Hopper, T., \& Rathnasiri, C. (2004). Japanese Cost Management Meets Sri Lankan Politics: Case Study of a Sri Lankan Public Utility. Accounting, Auditing and Accountability Journal, 17(1), 85-120.

Wickramasinghe, D., \& Hopper, T. (2005). A cultural political economy of management accounting controls: a case study of a textile Mill in a traditional Sinhalese village. Critical Perspectives on Accounting, 16(4), 473-503. doi:10.1016/j.cpa.2003.07.001

Willmott, R. (2000). The Place of Culture in Organization Theory: Introducing the Morphogenetic Approach. Organization, 7(1), 95-128. doi: 10.1177/135050840071006

Zaidi, S. (1999). Issues in Pakistan's Economy. New York, NY: Oxford University Press.

\footnotetext{
${ }^{\mathrm{i}}$ Regressive effects indicate the reform resulted in a deterioration of the very conditions that the reforms were trying to address.

ii The typical example of external relations is the state and business enterprises. While they influence each other but they can exist without the other to exist. The state and other institutions are considered as wider part of structural conditions in critical realism.
} 
iii Later research in institutional theory e.g., notions of institutional entrepreneurs or institutional change, does hint at the projective aspect of agency (Emirbayer and Mische, 1998; Mutch, 2007).

${ }^{\text {iv }}$ Recent works on institutional logics (Thornton et al., 2012) came close to critical realist conceptions of structure and agency but remain rooted on duality. Social actor is conceptualized as situated, embedded, and boundedly intentional individual having partial autonomy in Material ( resources, structures and practices) and Symbolic/ Cultural cognitive (ideation and meaning) setting.

${ }^{v}$ These documents included, for example, the review of Civil Aviation Ordinance 1984 along with its associated rules. This ordinance establishes the governance structure of the entity e.g. the Ministry of Defence, the Board of Directors, the Director General, and their powers and accountabilities. It also establishes the basic principles that govern the functioning of CAA, including various practices, such as accounting and budgeting. Other documents reviewed included the General Financial Rules of the Ministry of Finance, which are applicable to all public sector entities and departments. These rules establish the powers, and responsibilities of officers of these bodies/departments/ministries, especially with respect to cost control.

${ }^{\text {vi }} 10$ interviews with 5 change team members, 8 interviews with 7 reform agents including the DG and 26 interviews with managers including 4 functional heads, 21 senior managers and 1 official from ministry of defense. Multiple interviews were taken with some interviewees at different rounds.

${ }^{\text {vii }}$ We did not have access to the Prime Minster, the key agent for the reforms. An interview with him would have provided further insights into such a large-scale reform. Also, with hindsight, we feel that repeated interviews at different phases of the reform project with the same key agents, such as FR, would have been useful for providing a deeper understanding of agential strategies. This was not possible mainly because the reforms were already being implemented at CAA when we began our research project.

viii Three members of the change team were from the same directorate and were batch-mates and friends. Our interactions with the change team indicated that they held, more or less, similar views vis-à-vis the change efforts.

${ }^{\text {ix }}$ While we acknowledge, following the crtical realist tradtion, groups/collectivity such as reform agents and target poupulation find themselves in similar structural conditions, members of 'groups' are not always homogenous in their reception of these pressures, and formulation of strategies to deal with these pressures. This is the moment of agency in critical realist terms and is visible in a number of places in the paper.

${ }^{x}$ Project to Improve Financial Reporting and Auditing was a World Bank sponsored project that actually commenced in 1997 (\$29M). However, the scope of the project was enhanced considerably in the later years $\left(2^{\text {nd }}\right.$ phase: $\left.\$ 87 \mathrm{M}\right)$.

${ }^{x i}$ An air miss is a situation where two aircraft come dangerously close to each other, and where, due to a last minute and fortunate intervention by the pilots or controller, a mid-air collision is avoided.

xii According to ICAO standards, one air miss incident is acceptable per 32,000 air movements.

xiii Goal displacement and over-commitment were not found to be relevant in CAA's case. Sieber (1981) acknowledges that all seven mechanisms may not be at play in every episode of regressive reforms. 